\title{
Антигистаминные препараты в лечении аллергического ринита
}

А.Л. Гусева ${ }^{\circledR}$, ORCID: 0000-0002-7988-4229, e-mail: alexandra.guseva@gmail.com М.Л. Дербенева², ORCID: 0000-0002-8184-7312, e-mail: mlderbeneva@mail.ru

1 Российский национальный исследовательский медицинский университет им. Н.И. Пирогова; 117997, Россия, Москва, ул. Островитянова, д. 1

2 Городская клиническая больница №1 им. Н.И. Пирогова; 117049, Россия, Москва, Ленинский пр., д. 10

\section{Резюме}

Аллергический ринит является широко распространенным аллергическим заболеванием, оказывающим значительное негативное влияние на качество жизни пациентов. В терапии аллергического ринита большое значение имеет фармакотерапия, включающая применение антигистаминных средств, антагонистов лейкотриеновых рецепторов, топических стероидов, деконгестантов, кромонов, антихолинергических средств и их различных комбинаций. К часто назначаемым препаратам при легком, среднетяжелом и тяжелом течении заболевания относятся антигистаминные препараты. В статье рассматриваются механизмы действия антигистаминных препаратов первого и второго поколения, проводится сравнение возможных побочных эффектов и межлекарственного взаимодействия. Антигистаминные препараты первого поколения отличаются выраженным седативным и снотворным эффектом, в основном из-за своих выраженных липофильных свойств и способности проникать через гематоэнцефалический барьер и связываться с Н1-гистаминовыми рецепторами в ЦНС. Низкая селективность антигистаминных препаратов первого поколения обуславливает возможность их взаимодействия с другими рецепторами и развитие нежелательных побочных реакций, в том числе сухости во рту, носоглотке, реже расширения зрачков, повышения внутриглазного давления, тахикардии и задержки мочеиспускания. Биластин является высоко селективным антигистаминным препаратом второго поколения, имеющим быстрое начало и длительную продолжительность действия. Этот препарат не взаимодействует с системой цитохрома Р450 и не подвергается значительному метаболизму в организме человека, в связи с чем у препарата низкий потенциал межлекарственных взаимодействий. Биластин выводится практически без изменений и потому не требует корректировки дозы при почечной и печеночной недостаточности. Биластин продемонстрировал аналогичную с цетиризином и дезлоратадином эффективность у пациентов с сезонным аллергическим ринитом, а также аналогичную с цетиризином эффективность и безопасность в долгосрочном лечении пациентов с круглогодичным ринитом. Биластин хорошо переносится как в стандартных, так и в супратерапевтических дозах, обладает меньшим седативным потенциалом по сравнению с другими антигистаминными препаратами второго поколения и не обладает кардиотоксичностью.

Ключевые слова: аллергический ринит, антигистаминные препараты второго поколения, антигистаминные препараты первого поколения, биластин, седативный эффект

Для цитирования: Гусева А.Л.,Дербенева М.Л. Антигистаминные препараты в лечении аллергического ринита. Медицинский совет. 2020;(6):90-96. doі: 10.21518/2079-701Х-2020-6-90-96.

Конфликт интересов: авторы заявляют об отсутствии конфликта интересов.

\section{Antihistamines in the treatment of allergic rhinitis}

Alexandra L. Guseva ${ }^{1 凶}$, ORCID: 0000-0002-7988-4229, e-mail: alexandra.guseva@gmail.com

Maria L. Derbeneva², ORCID: 0000-0002-8184-7312, e-mail: mlderbeneva@mail.ru

${ }_{1}$ Pirogov Russian National Research Medical University; 1, Ostrovityanova St., Moscow, 117997, Russia

2 Pirogov City Clinical Hospital No1; 10, Leninsky Prospect, Moscow, 117049, Russia

\begin{abstract}
Allergic rhinitis is a common allergic disease that have a substantially negative impact on the patients' quality of life. Pharmacotherapy is essential to the treatment of allergic rhinitis, including the use of antihistamines, leukotriene receptor antagonists, topical steroids, decongestants, cromones, anticholinergics and their various combinations. Antihistamines are commonly prescribed drugs to treat mild, moderate, and severe disease. The article discusses the mechanisms of action of first- and second-generation antihistamines and compares the potential side effects and drug interactions.

First-generation antihistamines differ in their significant sedative and hypnotic effect, mainly due to their pronounced lipophilic properties and ability to transverse the blood-brain barrier and bind to H1-histamine receptors in the central nervous system. Due to low selectivity of the first-generation antihistamines, they may interact with other receptors and develop adverse side effects, including dry mouth, nasopharynx, more rarely pupillary dilation, increased intraocular pressure, tachycardia, and urine retention. Bilastine is a highly selective second-generation antihistamine that has a rapid onset and a prolonged action. This drug does not interact with the P450 cytochrome system or undergo significant
\end{abstract}


metabolism in the human body, and therefore the drug has low potential for drug-drug interactions. Bilastine is excreted almost completely unchanged and therefore does not require dose adjustment in patients with renal or hepatic impairment. Bilastine demonstrated similar efficacy in seasonal allergic rhinitis compared to cetirizine and desloratadine, as well as similar efficacy and safety in long-term treatment of patients with perennial rhinitis compared to cetirizine. Bilastine is well tolerated both at standard and at supratherapeutic doses, appears to have less sedative potential than other second-generation antihistamines, and has no cardiotoxicity.

Keywords: allergic rhinitis, second-generation antihistamines, first-generation antihistamines, bilastine, sedation

For citation: Guseva A.L., Derbeneva M.L. Antihistamines in the treatment of allergic rhinitis. Meditsinskiy sovet = Medical Council. 2020;(6):90-96. (In Russ.) doi: 10.21518/2079-701X-2020-6-90-96.

Conflict of interest: The authors declare no conflict of interest.

\section{ВВЕДЕНИЕ}

В основе аллергического ринита (АР) лежит аллергическая реакция I типа, а развитие IgE-опосредованного воспаления развивается при воздействии аллергенов на слизистую оболочку носа $[1,2]$. При специфическом связывании IgE со специализированными рецепторами FcعRI на тучных клетках и базофилах при повторном попадании антигена (аллергена) в организм и его распознавании из последних высвобождаются такие медиаторы, как гистамин, лейкотриен, фактор, активирующий тромбоциты, и др., вызывающие аллергические реакции немедленного типа [3, 4]. К триаде основных симптомов при АР относится пароксизмальное чихание, ринорея (водянистые выделения из носа) и заложенность носа. Помимо этого, для АР характерно появления зуда, чувства жжения в носу, а на поздних стадиях снижение обоняния. В зависимости от характера течения АР разделяют на интермиттирующую форму, при сохранении симптомов менее 4 дней в неделю или менее 4 недель в году, и на персистирующую форму, когда симптоматика присутствует более 4 дней в неделю и более 4 недель в году. Классификация по этиологическому фактору включает сезонный АР (поллиноз), круглогодичный/бытовой АР и профессиональный АР.

Эпидемиологические данные оценивают примерное количество страдающих АР в 500 млн человек по всему миру и 150 млн человек в Азиатско-Тихоокеанском регионе, где рост заболеваемости АР связывают с проживанием людей в перенаселенных мегаполисах с высоким уровнем загрязнения окружающей среды $[5,6]$. Так, в Японии заболеваемость АР увеличилась с 29,8\% в 1998 г. до 39,4\% в 2008 г., а также увеличилось количество случаев поллиноза [2]. В Китае только у 25\% заболевших АР диагностируется персистирующая форма, а у 75\% AP носит интермиттирующий характер [7].

Пациенты с АР часто обращаются к врачу амбулаторно, однако помимо основных симптомов заболевания их беспокоит нарушение сна, ухудшение качества жизни вследствие вынужденного снижения социальной активности на учебе или работе [8]. AР сам по себе может вызывать когнитивные нарушения, нарушение качества сна и появление дневной сонливости, что в том числе оказывает влияния на безопасность вождения [9].
По данным E.F. Vuurman et al. [10], у пациентов с AP, не получавших лечение, наблюдалось значительное снижение качества вождения автомобилем по сравнению с пациентами, у которых отсутствовали симптомы заболевания на фоне проводимого лечения, а при выполнении дополнительных когнитивных заданий (например, задач на запоминание) качество вождения еще больше ухудшалось и было сопоставимо с вождением пациентов, имеющих 0,05\% алкоголя в крови.

Лечение АР можно разделить на элиминационные мероприятия, включающие исключение или уменьшение контакта с аллергеном, медикаментозную и аллерген-специфическую иммунотерапию, крайне редко используются хирургические вмешательства. Среди перечисленных методов основное место занимает фармакотерапия, включающая применение антигистаминных средств, антагонистов лейкотриеновых рецепторов, топических стероидов, деконгестантов, кромонов, антихолинергических средств и их различных комбинаций. К часто назначаемым препаратам при легком, среднетяжелом и тяжелом течении заболевания относятся антигистаминные препараты (АГП), в том числе формы для перорального применения, глазные капли и интраназальные капли/спреи [2, 11]. По данным обсервационного исследования, проведенного в Азии, пациентам с AP чаще всего назначались АГП (более чем в 50\% случаев), в то время как топические стероиды получали около 30\% пациентов [12].

\section{СРАВНЕНИЕ АГП ПЕРВОГО И ВТОРОГО ПОКОЛЕНИЙ}

АГП давно представлены на рынке: самый первый из них, фенбензамин, появился в 1942 г. Принципиально важно, что они не обладают структурным сходством с

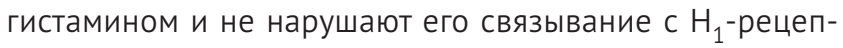
торами, однако при этом взаимодействуют с другими участками рецептора, переводя его в неактивное состояние. Таким образом, АГП являются обратными агонистами $\mathrm{H}_{1}$-рецепторов гистамина [13]. Самые первые АГП препараты первого поколения - отличались выраженным седативным и снотворным эффектом, в основном из-за своих выраженных липофильных свойств и способности проникать через гематоэнцефалический барьер и связываться с $\mathrm{H}_{1}$-гистаминовыми рецепторами 
в ЦНС. Низкая селективность АГП первого поколения обуславливает возможность их взаимодействия с другими рецепторами и развитие нежелательных побочных реакций. Так, связывание с мускариновыми рецепторами проявляется М-холиноблокирующим действием АГП, в том числе сухостью во рту, носоглотке, реже расширением зрачков, повышением внутриглазного давления, тахикардией и задержкой мочеиспускания [14]. АГП второго поколения были синтезированы и появлялись на рынке начиная с 1980 г. [15]. Эти препараты изначально отличались высокой селективностью к $\mathrm{H}_{1}$-рецепторам и минимальным седативным эффектом. Однако вследствие их различной специфичности к активным транспортным белкам (например, к Р-гликопротеину), способность проникать через гематоэнцефалический барьер различных представителей этой группы различается: так, цетиризин, дезлоратадин и лоратадин, особенно в больших дозах, оказывают более выраженный седативный эффект по сравнению с фексофенадином и левоцетризином [16]. Кардиотоксичность некоторых АГП второго поколения была выявлена в 1990х гг., после чего доказана и всесторонне изучена. Так, астемизол и терфенадин могут блокировать ионные каналы кардимиоцитов, способствовать удлинению интервала QT и возникновению опасных желудочковых аритмий по типу трепетания-мерцания, что привело в итоге к снятию их с производства. Эбастин и рупатадин, также имеющие кардиотоксический эффект, не рекомендуется применять пациентам при наличии удлиненного интервала QT и гипокалиемии [17].

Дальнейшая эволюция АГП второго поколения в основном базировалась на экспериментальной модификации предшествующих соединений первого поколения. Это привело к созданию так называемых стереоселективных форм, активных метаболитов, например левоцетиризина, и «метаболизируемых» АГП, приобретающих активность только после прохождения метаболизма в печени, например лоратадина. Одним из последних достижений является создание рупатадина - препарата с двойным эффектом: блокадой рецепторов фактора активации тромбоцитов и $\mathrm{H}_{1}$-гистаминовых рецепторов [18].

Биластин также является новым производным бензимидазола-пиперидина, высоко селективным АГП [19]. Он представляет собой отдельное химическое соединение и не является структурным производным от других препаратов этого класса [20]. На международный рынок он был выпущен в марте 2011 г. Его особенностью является длительное действие, что, по данным R. Bosma et al., связано с особенностями фармакокинетики препарата при его связывании с $\mathrm{H}_{1}$-рецепторами и более длительным нахождением на рецепторе-мишени. При этом срок действия биластина in vivo превосходит его фармакологически активные концентрации в крови [21].

\section{ТРЕБОВАНИЯ К ИДЕАЛЬНОМУ АГП}

В клинических рекомендациях ARIA (Allergic Rhinitis and its Impact on Asthma, Аллергический ринит и его вли- яние на астму) подчеркивается, что при назначении фармакотерапии пациенту с АР врач должен учитывать следующие факторы: эффективность, безопасность и экономическую целесообразность лечения, предпочтения пациента, цели лечения, предполагаемую приверженность лечению, степень тяжесть заболевания и возможность контроля лечения, а также наличие сопутствующих заболеваний [22]. В дополнение к этому клинические рекомендации также содержат подробный список характеристик, которым должны соответствовать пероральные АГП. Основополагающими среди этих свойств являются выраженная селективная блокирующая активность $\mathrm{H}_{1}$-рецепторов, быстрое начало и достаточная продолжительность действия, эффективность при аллергическом риноконъюнктивите и воздействие на все симптомы, включая заложенность носа, отсутствие взаимодействия с цитохромом P450 (СҮР 450), отсутствие седации, когнитивных или психомоторных нарушений, отсутствие антихолинергической активности, кардиотоксичности и предпосылок для развития тахифилаксии (снижения со временем терапевтического эффекта). Биластин, современный АГП второго поколения, в полной мере обладает вышеописанными характеристиками (табл.) [23].

\section{ОСОБЕННОСТИ ФАРМАКОЛОГИЧЕСКИХ СВОЙСТВ И КЛИНИЧЕСКОЙ ЭФФЕКТИВНОСТИ БИЛАСТИНА}

Биластин быстро всасывается после перорального приема. В экспериментах на крысах начало антигистаминных эффектов фиксировалось через 30 мин после приема, а максимальная эффективность сохранялась с 30 мин до 8 ч после приема, при этом продолжительность действия была около 16 ч [24]. При проведении исследования на здоровых добровольцах при приеме перорально 20 мг максимальная концентрация препарата в плазме крови наступаетчерез 1,3 ч.Биодоступность при этом составляет 61\%, однако одновременный прием пищи снижает ее на 30\%. В связи с этим рекомендуется принимать препарат между приемами пищи [25]. Биластин в организме человека метаболизируется незначительно, не взаимодействует с системой цитохрома P450, что сводит к минимуму потенциальную нежелательную возможность межлекарственных взаимодействий. Около 95\% однократной дозы выводится в неизмененном виде почками (28,3\%) и с желчью $(66,5 \%)$, в связи с этим не требуется коррекции дозы препарата при наличии у пациента печеночной и почечной недостаточности.

Проводилось сравнение эффективности биластина и других АГП при сезонном АР в мультицентровых рандомизированных двойных слепых плацебо-контролируемых исследованиях. В первом исследовании сравнивалась эффективность биластина и цетиризина в течение двух недель и была показана сравнимая эффективность обоих препаратов по сравнению с плацебо [26]. Во втором исследовании также была доказана эффективность биластина и дезлоратадина по сравнению с плацебо [27]. При круглогодичном АР в исследовании, проведенном 


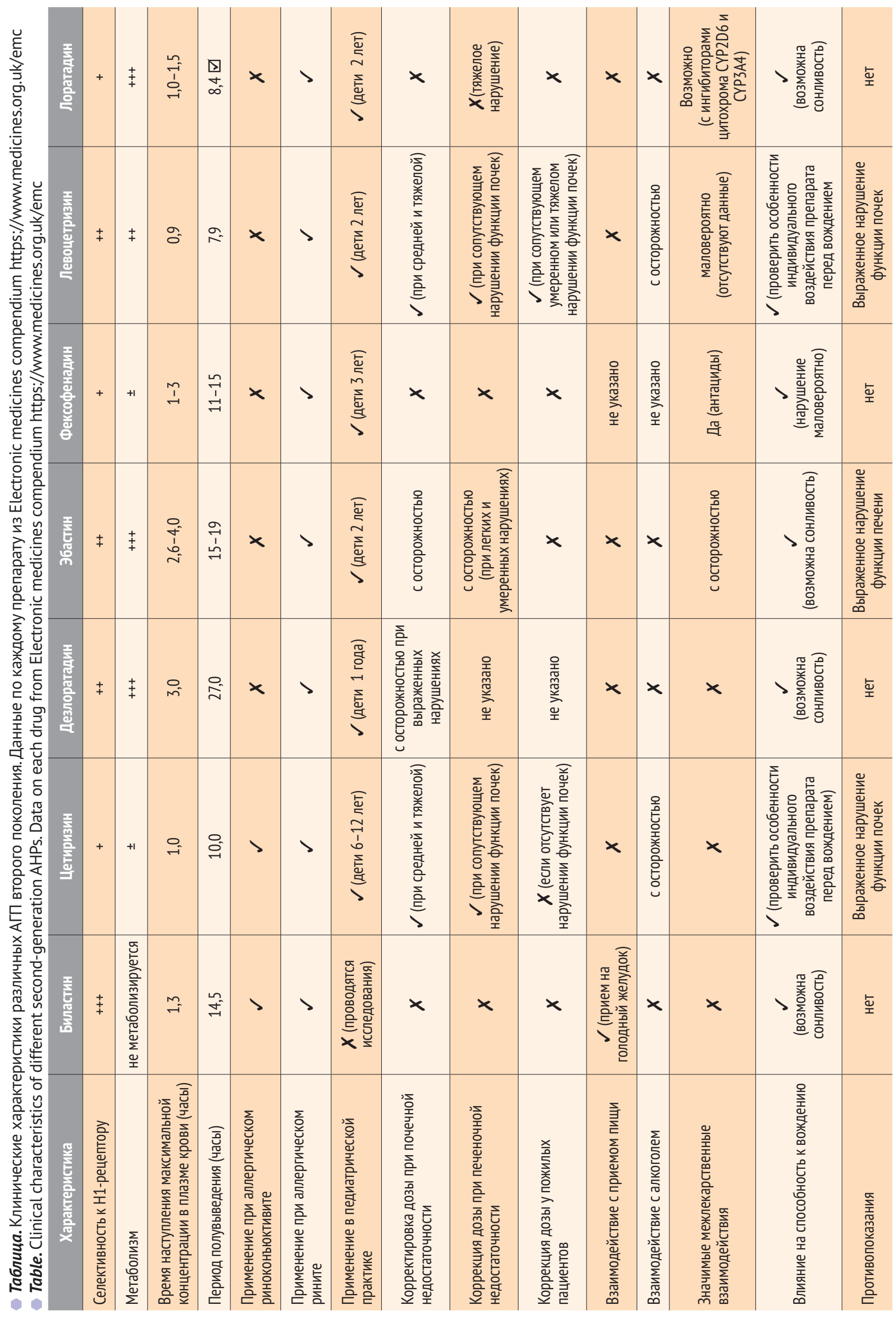


в Европе, Аргентине и Южной Африке, эффективность биластина сравнивалась с цетиризином и плацебо. Примечательно, что эффективность АГП по сравнению с плацебо была значительно выше в Европе и Аргентине, а длительное наблюдение показало безопасность и хорошую переносимость биластина [28]. В японском исследовании K. Okubo et al. подтверждена высокая эффективность и надежность биластина при его длительном приеме в дозировке 20 мг при приеме 1 раз в день в течение 12 недель [1]. В исследовании S. Conen et al. изучалось качество вождения добровольцев после приема гидроксизина, АГП первого поколения, стандартной дозы биластина (20 мг в день), большой дозы (40 мг в день). Результатом анализа характеристик вождения по автостраде было показано, что, в отличие от гидроксизина, биластин даже в больших дозировках не оказывает значимых психомоторных эффектов на качество вождения [29]. В работе A. Demonte et al. проводилось исследование влияние биластина на вождение автомобиля в условиях выполнения высокоскоростного вождения на симуляторе «Формулы 1» у водителейаллергиков после приема 20 мг биластина. При приеме биластина в течение 7 дней не было выявлено негативного влияния на способность водителей следовать намеченному маршруту, поддерживать необходимую скорость, а также сохранялся высокий уровень внимания и быстрая реакция в условиях экстремального вождения [30]. В многочисленных исследованиях не было выявлено значимого удлинения интервала ОT при приеме стандартных доз биластина [31].

В двойном слепом перекрестном исследовании F. Horak et al. проводилось сравнение эффективности действия биластина, цитиризина и фексофенадина для купирования симптомов аллергического ринита. У всех препаратов отмечена хорошая переносимость и эффективность, однако у биластина наблюдалось более длительное действие (более 26 ч после приема) по сравнению с другими препаратами [32]. R. Antonijoan et al. проводили сравнение эффективности биластина, дезло- ратадина и рупатадина по выраженности кожных высыпаний при внутрикожном введении гистамина у здоровых добровольцев. Биластин продемонстрировал наибольшее подавление местной аллергической реакции в течение 1-24 ч после введения гистамина по сравнению с другими препаратами, при этом начало действия биластина было самым быстрым (через 1 ч после введения, у других препаратов - 4 4) [33].

\section{ЗАКЛЮЧЕНИЕ}

Таким образом, учитывая высокий профиль безопасности, отсутствие седативного эффекта и вероятности межлекарственного взаимодействия в сочетании с высокой эффективностью купирования симптомов, можно рекомендовать биластин как один из базовых препаратов для лечения как интермиттирующего, так и персистирующего АР различной степени тяжести, включая аллергический риноконъюнктивит [34]. На отечественном рынке биластин представлен оригинальным препаратом Никсар ${ }^{\circledR}$. Препарат принимается один раз в сутки, т.к. его клинический эффект длится не менее 24 ч, а наступает уже через 1 ч после перорального приема. Принимать Никсар ${ }^{\circledR}$ следует за 1 ч до или через 2 ч после приема еды или фруктового сока, т.к. иначе наблюдается снижение биодоступности препарата. Никсар ${ }^{\circledR}$ практически не проявляет лекарственных взаимодействий с другими препаратами и не требует корректировки у пациентов с патологией печени и почек. Не выявлено негативного влияния препарат на какиелибо другие заболевания и противопоказаний к применению. Никсар ${ }^{\circledR}$ может применяться у детей с 12 лет и у пожилых пациентов без коррекции дозы. Детям в возрасте младше 12 лет Никсар ${ }^{\circledR}$ пока не рекомендован, но только потому, что исследования с этой возрастной группой еще продолжаются.

Поступила / Received 17.03.2020 Поступила после рецензирования / Revised 02.04.2020 Принята в печать / Accepted 22.04.2020

\section{Список литературы}

1. Астафьева Н.Г., Баранов А.А., Вишнева Е.А., Дайхес Н.А., Жестков А.В., Ильина Н.И. и др. Аллергический ринит. Клинические рекомендации Российской ассоциации аллергологов и клинических иммунологов, Национальной медицинской ассоциации оториноларингологов, Союза педиатров России, 2019. Режим доступа: http://raaci.ru/dat/pdf/allergic rhinitis-project.pdf.

2. Okubo K., Kurono Y., Ichimura K., Enomoto T., Okamoto Y., Kawauchi H. et al.; Japanese Society of Allergology. Japanese guidelines for allergic rhinitis 2017. Allergol Int. 2017;66(2):205-219. doi: 10.1016/j. alit.2016.11.001.

3. Wang D., Clement P., Smitz J., De Waele M., Derde M.P. Correlations between complaints, inflammatory cells and mediator concentrations in nasal secretions after nasal allergen challenge and during natural allergen exposure. Int Arch Allergy Immunol. 1995;106(3):278-285. doi: 10.1159/000236855.

4. Хаитов Р.М., Ильина Н.И. (ред.). Аллергология и иммунология: наииональное руководство. М.: ГЭОТАР-Медиа; 2009. 656 с. Режим доступа: https:// www.rosmedlib.ru/book/ISBN9785970409039.html.

5. Pawankar R., Bunnag C., Khaltaev N., Bousquet J. Allergic Rhinitis and Its Impact on Asthma in Asia Pacific and the ARIA Update 2008. World Allergy Organ J. 2012;5(3):212-217. doi: 10.1097/WOX.0b013e318201d831.
6. Kulthanan K., Chusakul S., Recto M.T., Gabriel M.T., Aw D.C.W., Prepageran N. et al. Economic Burden of the Inadequate Management of Allergic Rhinitis and Urticaria in Asian Countries Based on the GA2LEN Model. Allergy Asthma Immunol Res. 2018;10(4):370-378. doi: 10.4168/aair.2018.10.4.370.

7. Zhang L., Han D., Huang D., Wu Y., Dong Z., Xu G. et al. Prevalence of selfreported allergic rhinitis in eleven major cities in China. Int Arch Allergy Immunol. 2009;149(1):47-57. doi: 10.1159/000176306.

8. Angier E., Willington J., Scadding G., Holmes S., Walker S. Management of allergic and non-allergic rhinitis: a primary care summary of the BSACI guideline. Prim Care Respir J. 2010;19(3):217-222. doi: 10.4104/ pcrj.2010.00044

9. Colás C., Galera H., Añibarro B., Soler R., Navarro A., Jáuregui I., Peláez A. Disease severity impairs sleep quality in allergic rhinitis (The SOMNIAAR study). Clin Exp Allergy. 2012;42(7):1080-1087. doi: 10.1111/j.1365-2222.2011.03935.x.

10. Vuurman E.F., Vuurman L.L., Lutgens I., Kremer B. Allergic rhinitis is a risk factor for traffic safety. Allergy. 2014;69(7):906-912. doi: 10.1111/ all.12418.

11. Mandhane S.N., Shah J.H., Thennati R. Allergic rhinitis: an update on disease, present treatments and future prospects. Int Immunopharmacol. 2011;11(11):1646-1662. doi: 10.1016/j.intimp.2011.07.005. 
12. Wang Y., Ghoshal A.G., Bin Abdul Muttalif A.R., Lin H.-C., Thanaviratananich S., Bagga S. et al. Quality of Life and Economic Burden of Respiratory Disease in Asia-Pacific - Asia-Pacific Burden of Respiratory Diseases Study. Value Health Reg Issues. 2016;9:72-77. doi: 10.1016/j. vhri.2015.11.004

13. Соболенко Т.М. Применение Н1-антигистаминных средств в клинической практике: проблемы и решения. Медицинские новости. 2016;(3):4-9. Режим доступа: https://cyberleninka.ru/article/n/primenenie-n1antigistaminnyh-sredstv-v-klinicheskoy-praktike-problemy-i-resheniya.

14. Kawauchi H., Yanai K., Wang D.Y., Itahashi K., Okubo K. Antihistamines for Allergic Rhinitis Treatment from the Viewpoint of Nonsedative Properties. Int J Mol Sci. 2019;20(1):213. doi: 10.3390/ijms20010213.

15. Church M.K., Church D.S. Pharmacology of antihistamines. Indian J Dermatol. 2013;58(3):219-224. doi: 10.4103/0019-5154.110832.

16. Wallace D.V., Dykewicz M.S., Bernstein D.I., Blessing-Moore J., Cox L., Khan D.A. et al. The diagnosis and management of rhinitis: an updated practice parameter. J Allergy Clin Immunol. 2008;122(2):1-84. doi: 10.1016/j.jaci.2008.06.003.

17. Карева Е.Н. Выбор антигистаминного препарата: взгляд фармаколога. РМЖ. 2016;(12):811-816. Режим доступа: https://www.rmj.ru/articles/ allergologiya/vybor-antigistaminnogo-preparata-vzglyad-farmakologa5803/

18. Picado C. Rupatadine: pharmacological profile and its use in the treatment of allergic disorders. Expert Opin Pharmacother. 2006;7(14):19892001. doi: 10.1517/14656566.7.14.1989.

19. Kowal K., DuBuske L. Bilastine as a potential treatment in allergic rhinitis Am J Rhinol Allergy. 2014;28(4):312-316. doi: 10.2500/ajra.2014.28.4049.

20. Wolthers O.D. Bilastine: a new nonsedating oral $\mathrm{H} 1$ antihistamine for treatment of allergic rhinoconjunctivitis and urticaria. Biomed Res Int. 2013;2013:626837. doi: 10.1155/2013/626837.

21. Bosma R., van den Bor J., Vischer H.F., Labeaga L., Leurs R. The long duration of action of the second generation antihistamine bilastine coincides with its long residence time at the histamine $\mathrm{H} 1$ receptor. Eur J Pharmacol. 2018;838:107-111. doi: 10.1016/j.ejphar.2018.09.011.

22. Brożek J.L., Bousquet J., Agache I., Agarwal A., Bachert C., Bosnic-Anticevich S. et al. Allergic Rhinitis and its Impact on Asthma (ARIA) guidelines - 2016 revision. J Allergy Clin Immunol. 2017;140(4):950-958. doi: 10.1016/j. jaci.2017.03.050.

23. Recto M.T., Gabriel M.T., Kulthanan K., Tantilipikorn P., Aw D.C., Lee T.H. et al. Selecting optimal second-generation antihistamines for allergic rhinitis and urticaria in Asia. Clin Mol Allergy. 2017;15:19. doi: 10.1186/s12948 017-0074-3.

24. Jauregizar N., de la Fuente L., Lucero M.L., Sologuren A., Leal N., Rodríguez M. Pharmacokinetic-pharmacodynamic modelling of the antihistaminic $(\mathrm{H} 1)$ effect of bilastine. Clin Pharmacokinet. 2009;48(8):543-554. doi: 10.2165/11317180-000000000-00000.

25. Sádaba B., Gómez-Guiu A., Azanza J.R., Ortega I., Valiente R. Oral availability of bilastine. Clin Drug Investig. 2013;33(5):375-381. doi: 10.1007/ s40261-013-0076-y.

26. Kuna P., Bachert C., Nowacki Z., van Cauwenberge P., Agache I., Fouquert L. et al.; Bilastine International Working Group. Efficacy and safety of bilastine $20 \mathrm{mg}$ compared with cetirizine $10 \mathrm{mg}$ and placebo for the symptomatic treatment of seasonal allergic rhinitis: a randomized, doubleblind, parallel-group study. Clin Exp Allergy. 2009;39(9):1338-1347. doi: 10.1111/j.1365-2222.2009.03257.x

27. Bachert C., Kuna P., Sanquer F., Ivan P., Dimitrov V., Gorina M.M. et al; Bilastine International Working Group. Comparison of the efficacy and safety of bilastine $20 \mathrm{mg}$ vs desloratadine $5 \mathrm{mg}$ in seasonal allergic rhinitis patients. Allergy. 2009;64(1):158-165. doi: 10.1111/j.1398-9995.2008.01813.x.

28. Annesi-Maesano I., Beyer A., Marmouz F., Mathelier-Fusade P., Vervloet D., Bauchau V. Concurrent allergic diseases: a cross-sectional study in a French population. Allergy. 2006;61(3):390-391. doi: 10.1111/j.1398-9995.2006.01019.x.

29. Conen S., Theunissen E.L., Van Oers A.C., Valiente R., Ramaekers J.G. Acute and subchronic effects of bilastine (20 and $40 \mathrm{mg}$ ) and hydroxyzine (50 mg) on actual driving performance in healthy volunteers. J Psychopharmacol. 2011;25(11):1517-1523. doi: 10.1177/0269881110382467.

30. Demonte A., Guanti M.B., Liberati S., Biffi A., Fernando F., Fainello M., Pepe P. Bilastine safety in drivers who need antihistamines: new evidence from high-speed simulator driving test on allergic patients. Eur Rev Med Pharmacol Sci. 2018;22(3):820-828. doi: 10.26355/eurrev_201802_14318.

31. Graff C., Struijk J.J., Kanters J.K., Andersen M.P., Toft E., Tyl B. Effects of bilastine on T-wave morphology and the QTC interval: a randomized, doubleblind, placebo-controlled, thorough OTC study. Clin Drug Investig. 2012;32(5):339-351. doi: 10.2165/11599270-000000000-00000.

32. Horak F., Zieglmayer P., Zieglmayer R., Lemell P. The effects of bilastine compared with cetirizine, fexofenadine, and placebo on allergen-induced nasal and ocular symptoms in patients exposed to aeroallergen in the Vienna Challenge Chamber. Inflamm Res. 2010;59(5):391-398. doi: 10.1007/s00011-009-0117-4.

33. Antonijoan R., Coimbra J., García-Gea C., Puntes M., Gich I., Campo C. et al. Comparative efficacy of bilastine, desloratadine and rupatadine in the suppression of wheal and flare response induced by intradermal histamine in healthy volunteers. Curr Med Res Opin. 2017;33(1):129-136. doi: 10.1080/03007995.2016.1240665.

34. Church M.K., Tiongco-Recto M., Ridolo E., Novák Z. Bilastine: a lifetime companion for the treatment of allergies. Curr Med Res Opin. 2020;36(3):445-454. doi: 10.1080/03007995.2019.1681134.

\section{References}

1. Astaf'eva N.G.,Baranov A.A., Vishneva E.A., Daykhes N.A., ZHestkov A.V., Il'ina N.I. et al. Allergic rhinitis. Clinical guidelines of the Russian Association of Allergologists and Clinical Immunologists, the National Medical Association of Otorhinolaryngologists, the Union of Pediatricians of Russia, 2019. (In Russ.) Available at: http://raaci.ru/dat/pdf/allergic_rhinitis-project.pdf.

2. Okubo K., Kurono Y., Ichimura K., Enomoto T., Okamoto Y., Kawauchi H. et al.; Japanese Society of Allergology. Japanese guidelines for allergic rhinitis 2017. Allergol Int. 2017;66(2):205-219. doi: 10.1016/j.alit.2016.11.001.

3. Wang D., Clement P., Smitz J., De Waele M., Derde M.P. Correlations between complaints, inflammatory cells and mediator concentrations in nasal secretions after nasal allergen challenge and during natural allergen exposure. Int Arch Allergy Immunol. 1995;106(3):278-285. doi: 10.1159/000236855.

4. Khaitov R.M., Il'ina N.I. (eds.). Allergology and immunology: national guidelines. Moscow: GEOTAR-Media; 2009. 656 p. (In Russ.) Available at: https:// www.rosmedlib.ru/book/ISBN9785970409039.html.

5. Pawankar R., Bunnag C., Khaltaev N., Bousquet J. Allergic Rhinitis and Its Impact on Asthma in Asia Pacific and the ARIA Update 2008. World Allergy Organ J. 2012;5(3):212-217. doi: 10.1097/WOX.0b013e318201d831.

6. Kulthanan K., Chusakul S., Recto M.T., Gabriel M.T., Aw D.C.W., Prepageran N. et al. Economic Burden of the Inadequate Management of Allergic Rhinitis and Urticaria in Asian Countries Based on the GA²LEN Model. Allergy Asthma Immunol Res. 2018;10(4):370-378. doi: 10.4168/aair.2018.10.4.370.

7. Zhang L., Han D., Huang D., Wu Y., Dong Z., Xu G. et al. Prevalence of selfreported allergic rhinitis in eleven major cities in China. Int Arch Allergy Immunol. 2009;149(1):47-57. doi: 10.1159/000176306.

8. Angier E., Willington J., Scadding G., Holmes S., Walker S. Management of allergic and non-allergic rhinitis: a primary care summary of the BSACl guideline. Prim Care Respir J. 2010;19(3):217-222. doi: 10.4104/pcrj.2010.00044.
9. Colás C., Galera H., Añibarro B., Soler R., Navarro A., Jáuregui I., Peláez A. Disease severity impairs sleep quality in allergic rhinitis (The SOMNIAAR study). Clin Exp Allergy. 2012;42(7):1080-1087. doi: 10.1111/j.1365-2222.2011.03935.x.

10. Vuurman E.F., Vuurman L.L., Lutgens I., Kremer B. Allergic rhinitis is a risk factor for traffic safety. Allergy. 2014;69(7):906-912. doi: 10.1111/all.12418.

11. Mandhane S.N., Shah J.H., Thennati R. Allergic rhinitis: an update on disease, present treatments and future prospects. Int Immunopharmacol. 2011;11(11):1646-1662. doi: 10.1016/j.intimp.2011.07.005.

12. Wang Y., Ghoshal A.G., Bin Abdul Muttalif A.R., Lin H.-C., Thanaviratananich S., Bagga S. et al. Quality of Life and Economic Burden of Respiratory Disease in Asia-Pacific - Asia-Pacific Burden of Respiratory Diseases Study. Value Health Reg Issues. 2016;9:72-77. doi: 10.1016/j.vhri.2015.11.004.

13. Sobolenko T.M. Clinical use of $\mathrm{H} 1$-antihistamines: problems and solutions. Meditsinskie novosti = Medical News. 2016;(3):4-9. (In Russ.) Available at: https://cyberleninka.ru/article/n/primenenie-n1-antigistaminnyh-sredstvv-klinicheskoy-praktike-problemy-i-resheniya.

14. Kawauchi H., Yanai K., Wang D.Y., Itahashi K., Okubo K. Antihistamines for Allergic Rhinitis Treatment from the Viewpoint of Nonsedative Properties. Int J Mol Sci. 2019;20(1):213. doi: 10.3390/ijms20010213.

15. Church M.K., Church D.S. Pharmacology of antihistamines. Indian J Dermatol. 2013;58(3):219-224. doi: 10.4103/0019-5154.110832.

16. Wallace D.V., Dykewicz M.S., Bernstein D.I., Blessing-Moore J., Cox L., Khan D.A. et al. The diagnosis and management of rhinitis: an updated practice parameter. J Allergy Clin Immunol. 2008;122(2):1-84. doi: 10.1016/j.jaci.2008.06.003.

17. Kareva E.N. The choice of an antihistamine drug: a view of a pharmacologist. $R M Z H=R M J .2016 ;(12): 811-816$. (In Russ.) Available at: https://www. rmj.ru/articles/allergologiya/vybor-antigistaminnogo-preparata-vzglyadfarmakologa5803. 
18. Picado C. Rupatadine: pharmacological profile and its use in the treatment of allergic disorders. Expert Opin Pharmacother. 2006;7(14):19892001. doi: 10.1517/14656566.7.14.1989.

19. Kowal K., DuBuske L. Bilastine as a potential treatment in allergic rhinitis. Am J Rhinol Allergy. 2014;28(4):312-316. doi: 10.2500/ajra.2014.28.4049.

20. Wolthers O.D. Bilastine: a new nonsedating oral $\mathrm{H} 1$ antihistamine for treatment of allergic rhinoconjunctivitis and urticaria. Biomed Res Int 2013;2013:626837. doi: 10.1155/2013/626837.

21. Bosma R., van den Bor J., Vischer H.F., Labeaga L., Leurs R. The long duration of action of the second generation antihistamine bilastine coincides with its long residence time at the histamine $\mathrm{H} 1$ receptor. Eur J Pharmacol. 2018;838:107-111. doi: 10.1016/j.ejphar.2018.09.011.

22. Brożek J.L., Bousquet J., Agache I., Agarwal A., Bachert C., Bosnic-Anticevich S. et al. Allergic Rhinitis and its Impact on Asthma (ARIA) guidelines - 2016 revision. J Allergy Clin Immunol. 2017;140(4):950-958. doi: 10.1016/j.jaci.2017.03.050.

23. Recto M.T., Gabriel M.T., Kulthanan K., Tantilipikorn P., Aw D.C., Lee T.H. et al. Selecting optimal second-generation antihistamines for allergic rhinitis and urticaria in Asia. Clin Mol Allergy. 2017;15:19. doi: 10.1186/s12948017-0074-3.

24. Jauregizar N., de la Fuente L., Lucero M.L., Sologuren A., Leal N., Rodríguez M. Pharmacokinetic-pharmacodynamic modelling of the antihistaminic (H1) effect of bilastine. Clin Pharmacokinet. 2009;48(8):543-554. doi: 10.2165/11317180-000000000-00000

25. Sádaba B., Gómez-Guiu A., Azanza J.R., Ortega I., Valiente R. Oral availability of bilastine. Clin Drug Investig. 2013;33(5):375-381. doi: 10.1007/ s40261-013-0076-y.

26. Kuna P., Bachert C., Nowacki Z., van Cauwenberge P., Agache I., Fouquert L. et al. Efficacy and safety of bilastine $20 \mathrm{mg}$ compared with cetirizine $10 \mathrm{mg}$ and placebo for the symptomatic treatment of seasonal allergic rhinitis: a randomized, double-blind, parallel-group study. Clin Exp Allergy. 2009;39(9):1338-1347. doi: 10.1111/j.1365-2222.2009.03257.x.
27. Bachert C., Kuna P., Sanquer F., Ivan P., Dimitrov V., Gorina M.M. et al; Bilastine International Working Group. Comparison of the efficacy and safety of bilastine $20 \mathrm{mg}$ vs desloratadine $5 \mathrm{mg}$ in seasonal allergic rhinitis patients. Allergy. 2009;64(1):158-165. doi: 10.1111/j.1398-9995.2008.01813.x.

28. Annesi-Maesano I., Beyer A., Marmouz F., Mathelier-Fusade P., Vervloet D. Bauchau V. Concurrent allergic diseases: a cross-sectional study in a French population. Allergy. 2006;61(3):390-391. doi:10.1111/j.1398-9995.2006.01019.x

29. Conen S., Theunissen E.L., Van Oers A.C., Valiente R., Ramaekers J.G. Acute and subchronic effects of bilastine (20 and $40 \mathrm{mg}$ ) and hydroxyzine $(50 \mathrm{mg})$ on actual driving performance in healthy volunteers. J Psychopharmacol. 2011;25(11):1517-1523. doi: 10.1177/0269881110382467.

30. Demonte A., Guanti M.B., Liberati S., Biffi A., Fernando F., Fainello M., Pepe P. Bilastine safety in drivers who need antihistamines: new evidence from high-speed simulator driving test on allergic patients. Eur Rev Med Pharmacol Sci. 2018;22(3):820-828. doi: 10.26355/eurrev_201802_14318.

31. Graff C., Struijk J.J., Kanters J.K., Andersen M.P., Toft E., Tyl B. Effects of bilastine on T-wave morphology and the QTc interval: a randomized, doubleblind, placebo-controlled, thorough QTC study. Clin Drug Investig. 2012;32(5):339-351. doi: 10.2165/11599270-000000000-00000.

32. Horak F., Zieglmayer P., Zieglmayer R., Lemell P. The effects of bilastine compared with cetirizine, fexofenadine, and placebo on allergen-induced nasal and ocular symptoms in patients exposed to aeroallergen in the Vienna Challenge Chamber. Inflamm Res. 2010;59(5):391-398. doi: 10.1007/s00011-009-0117-4.

33. Antonijoan R., Coimbra J., García-Gea C., Puntes M., Gich I., Campo C. et al. Comparative efficacy of bilastine, desloratadine and rupatadine in the suppression of wheal and flare response induced by intradermal histamine in healthy volunteers. Curr Med Res Opin. 2017;33(1):129-136. doi: 10.1080/03007995.2016.1240665.

34. Church M.K., Tiongco-Recto M., Ridolo E., Novák Z. Bilastine: a lifetime companion for the treatment of allergies. Curr Med Res Opin. 2020;36(3):445 -454. doi: 10.1080/03007995.2019.1681134.

\section{Информация об авторах:}

Гусева Александра Леонидовна, к.М.н. доцент, кафедра оториноларингологии им. акад. Б.С. Преображенского, Федеральное государственное автономное образовательное учреждение высшего образования «Российский национальный исследовательский медицинский университет им. Н.И. Пирогова» Министерства здравоохранения Российской Федерации; 117997, Россия, Москва, ул. Островитянова, д. 1; e-mail: alexandra.guseva@gmail.com

Дербенева Мария Львовна, к.М.н., врач-оториноларинголог, Государственное бюджетное учреждение здравоохранения города Москвы «Городская клиническая больница №1 им. Н.И. Пирогова» Департамента здравоохранения города Москвы; 117049, Россия, Москва, Ленинский пр., д. 10; e-mail: mlderbeneva@mail.ru

\section{Information about the authors:}

Alexandra L. Guseva, Cand. of Sci. (Med.), Associate Professor, Department of Otorhinolaryngology named after Academician B.S. Preobrazhensky, Federal State Autonomous Educational Institution of Higher Education "N.I. Pirogov Russian National Research Medical University" of the Ministry of Health of the Russian Federation; 1, Ostrovityanova St., Moscow, 117997, Russia; e-mail: alexandra. guseva@gmail.com

Mariya L. Derbeneva, Cand. of Sci. (Med.), Otorhynolaryngologist, State Budget Healthcare Institution of Moscow "Pirogov City Clinical Hospital No. 1" of the Department of Health of Moscow; 10, Leninskiy Ave., Moscow, 117049, Russia; e-mail: mlderbeneva@mail.ru 